\title{
Invariant Properties of Solid Oxide Fuel Cell Systems with Integrated Reformers
}

\author{
Andrew Slippey ${ }^{\mathrm{a}}$, Omid Madani ${ }^{\mathrm{b}}$, Kalyan Nishtala ${ }^{\mathrm{a}}$, Tuhin Das ${ }^{\mathrm{c}, *}$ \\ ${ }^{a}$ Graduate Student, Rochester Institute of Technology, Rochester, NY \\ ${ }^{b}$ PhD Student, University of Central Florida, Orlando, $F L$ \\ ${ }^{c}$ Assistant Prof., Mech. \& Aero. Engg. Dept., Univ. of Central Florida Orlando, FL 32816
}

\begin{abstract}
In reformer based Solid Oxide Fuel Cells (SOFCs) with hydrocarbon fuels, fuel utilization (U) and steam-to-carbon-ratio (STCR) are important variables indicating conditions inside the anode and reformer respectively. However, both variables are difficult to measure due to their dependence on internal species concentrations, temperatures, pressures and flow rates. In contrast to systemspecific model-based techniques for estimating U and STCR, this paper proposes a generalized method for formulating and characterizing these variables, that applies to hydrocarbon fuels of the form $\mathrm{C}_{a} \mathrm{H}_{2 b} \mathrm{O}_{d}$, multiple reformer types, and system configurations. The approach takes advantage of the invariance of quantities, such as potential hydrogen and steam-to-carbon-balance (STCB), with respect to reaction pathways, reaction rates, and aforementioned internal conditions. These conserved quantities can be predicted under steady-state conditions in a model-independent fashion. The invariant relationships so obtained are useful for predicting U and STCB using only system level inputs, namely current, supply rate of unreformed fuel, and rate of recirculation, and without requiring expensive and intrusive sensors. They are also useful for maintaining $\mathrm{U}$ and STCB at target values and in addressing their transient fluctuations.

Keywords: Solid oxide fuel cell, Reformer, Steam-to-carbon-ratio, Fuel utilization
\end{abstract}

*Address all correspondence to this author: tuhin.das@ucf.edu

Preprint submitted to Energy

July 1, 2015

(C) 2015. This manuscript version is made available under the Elsevier user license http://www.elsevier.com/open-access/userlicense/1.0/ 


\section{Nomenclature}

\begin{tabular}{ll}
$a, b, d$ & C, H, and O content of hydrocarbon $\mathrm{C}_{a} \mathrm{H}_{2 b} \mathrm{O}_{d}$ \\
$F$ & Faraday's constant, 96485.34 Coulomb $/$ mol \\
$i$ & Fuel cell current, $A$ \\
$k$ & Anode recirculation fraction \\
$N$ & Number of moles, moles \\
$\dot{N}_{\text {air }}$ & Molar flow rate of air, moles $/ s$ \\
$\dot{N}_{f}$ & Molar flow rate of fuel, moles $/ s$ \\
$\dot{N}_{\text {in }}$ & Anode inlet flow rate, moles $/ s$ \\
$\dot{N}_{o}$ & Anode exit flow rate, moles $/ s$ \\
$n$ & Number of electrons participating in electro-chemical reaction, $(=2)$ \\
$\mathbf{P}$ & Potential hydrogen vector \\
$p$ & Species potential hydrogen \\
$\mathbf{Q}$ & Potential steam vector \\
$q$ & Species potential steam \\
$r_{I}, r_{I I}, r_{I I I}$ & Rates of reforming reactions I, II and III, moles $/ s$ \\
$r_{e}$ & Rate of electro-chemical reaction, moles $/ s$ \\
$S T C R$ & Steam-to-carbon-ratio \\
$S T C B$ & Steam-to-carbon-balance moles $/ s$ \\
$U$ & Utilization \\
$\mathcal{N}$ & Number of cells \\
$\mathcal{R}$ & Species rate of formation, moles $/ s$ \\
\hline Subscripts & Species mole fraction \\
$a$ & Anode control volume \\
$s s$ & Reformer control volume \\
\hline &
\end{tabular}

\section{Introduction}

SOFCs are high temperature energy conversion devices with advantages such 5 as high efficiency, fuel flexibility, and tolerance to impurities. They operate at 
high temperatures $\left(800^{\circ}-1000^{\circ} \mathrm{C}\right)$ that allow internal reforming by promoting rapid reaction kinetics with non-precious metal catalysts, [1, 2, 3]. SOFCs produce high quality by-product heat for co-generation or for use in a bottoming cycle, 4 4, 5, 6]. As with other types of fuel cells such as PEMFC (Polymer Electrolyte Membrane Fuel Cells), SOFCs generate power by electro-chemical oxidation rather than the traditional combustion of fuel. However unlike PEMFCs which conduct hydrogen ions, SOFCs conduct oxygen ions through their electrolytes. Also, unlike PEMFCs which are poisoned by very small amounts of carbon monoxide (CO), SOFCs are tolerant to $\mathrm{CO}$ and use it in addition to hydrogen in its electrochemical reactions [7]. In typical SOFCs, the anode, cathode and electrolyte are made of ceramics. These layers are arranged in either a tubular or a planar geometry. Due to the combination of its unique advantages, SOFCs find application in distributed and stationary power generation, such as residential and industrial applications with power ranging from 1-1000 kW. Natural gas can be used as fuel for such applications.

In spite of these favorable attributes, SOFCs have certain drawbacks. Poisoning of SOFC electrodes, primarily through trace sulfur in fuel, causes performance degradation. It is addressed by additionally desulfurizing the fuel before feeding it to the fuel cell. The high temperature operation poses significant 25 challenge to the mechanical integrity and longevity of individual cells. It also increases the product cost. As a result, research on SOFC materials are actively pursued and medium temperature SOFCs operating at around $600^{\circ} \mathrm{C}$ are also of great interest. From a system and control standpoint, poor load following capability of SOFCs poses performance limitations [8], especially under rapid load variations. This issue, which is of interest in this paper, is attributed to the slow dynamic response of the fuel delivery systems consisting of valves, pumps and reformers, $[9,10,11,12]$. The phenomenon is manifested as hydrogen starvation and it adversely affects cell durability through anode oxidation [12] and reversal of cell potential, leading to catalyst corrosion [13].

In SOFCs, availability of hydrogen is closely related to a parameter named fuel utilization $U$. It is defined as the ratio of hydrogen consumption to the 
net available hydrogen in the anode of an SOFC. While high utilization implies high efficiency [14], very high utilization leads to reduced partial pressure of hydrogen in the anode, leading to voltage drop [12]. Typically, $80-90 \%$ is 40 set as the target range, [15, 16, 17, 18], for optimal efficiency. Values close to $100 \%$ indicate the onset of fuel starvation. Constant $U$ operation of SOFCs $[19,20,21,22]$ is particularly suited to address fuel starvation. One way to maintain constant $U$ is to vary fuel flow rate assuming $U$ is measured, [23, 19]. While this is acceptable in simulations, in practice measuring $U$ requires 45 several species-specific concentration sensors that are avoided due to cost and reliability considerations [14]. Model-based estimation can be used but they are computationally intensive and rely on the accuracy of models [24, 25, 26]. Another method is to use an analytical equation relating $U$, fuel flow, and current draw in steady-state. The equation is used to manipulate fuel flow based on current demand. A generalization of this method is of interest in this work.

It is noteworthy that for Polymer Electrolyte Membrane (PEM) fuel cells oxygen starvation, rather than hydrogen starvation, is a greater issue. There, existing methods of mitigation include reference governors [27, 28], or Model

${ }_{55}$ Predictive Control (MPC) [29, 11]. Hydrogen starvation in SOFCs and oxygen starvation in PEMs have similar consequences, such as excessive drop in cell voltage. However, SOFCs and PEMs are sufficiently different technologies to necessitate completely different approaches for addressing these phenomena. Most importantly, the fuel supply to SOFC anode is a gas mixture containing several species with varying and unknown concentrations due to fuel flexibility and internal reforming. In contrast, in PEMs the air supply has a fixed and known amount of oxygen. This is an important reason why model-based control of SOFCs poses challenges but is more tractable for PEMs.

In addition to starvation, carbon deposition is a common issue in reformerbased SOFCs [30, 31]. It can jeopardize the health of catalysts in both reformer and anode. To address this issue, some works have developed control strategies that are sensitive with respect to carbon deposition [32], and others have focused 
specific types of fuels [33, 34]. Another approach is to control the steam-tocarbon-ratio $S T C R$ in the reformer. While $U$ is a vital parameter determining tems and hydrocarbon fuels of the form $\mathrm{C}_{a} \mathrm{H}_{2 b} \mathrm{O}_{d}$, steady-state $U$ and steamto-carbon-balance $S T C B$ (related to $S T C R$ ) can be predicted from the input variables, namely current draw, flow rate and composition of the unreformed fuel, and recirculation fraction. For such systems, steady-state $U$ and $S T C B$ and pressures. Hence, they can be predicted simply from system-level inputs, with minimal sensor requirement and without knowledge of the system model. We term such relationships as invariant properties. We develop an analytical framework that allows us to derive these properties in a generalized form, framework emerges from our prior works with specific SOFC systems and fuels, [37, 38], and is based on the observation that variables such as potential hydrogen and potential steam are conserved in the reforming process. Although somewhat related methods has been suggested for specific SOFCs in the literature [39, 20], fuels or to a class of SOFCs has not yet been reported. The idea of maximum extractable hydrogen through reforming appeared in a few works, 40]. However an analytical development of the idea did not appear. A formulation of $U$ as a function of current, fuel flow rate and recirculation was established, [2], but 95 without explicitly incorporating the rates of reforming reactions in the analysis. Also the type of fuels considered was limited and an extension to $S T C R$ did not appear in the work.

The ability to predict steady-state $U$ and $S T C B$ based on input conditions 
is advantageous, since it allows us to determine operating points that are safe aforementioned recirculated anode flow, as shown in Fig 1. The remaining anode efflux is mixed with the cathode exhaust flow in the combustion chamber. The 
combustor also serves to preheat the cathode air which has a molar flow rate of $\dot{N}_{\text {air }}$. The tubular construction of each cell causes the air to first enter the cell through the air supply tube and then reverse its direction to enter the cathode chamber. The cathode air serves as the source of oxygen for the fuel cell.

\subsection{Mass Balance Equations}

The main reactions representing steam reforming of methane are [23], [49]:

$$
\begin{array}{rrlll}
\text { (I) } \mathrm{CH}_{4}+\mathrm{H}_{2} \mathrm{O} & \leftrightarrow \mathrm{CO}+3 \mathrm{H}_{2}, \quad \text { (II) } \mathrm{CO}+\mathrm{H}_{2} \mathrm{O} & \leftrightarrow & \mathrm{CO}_{2}+\mathrm{H}_{2} \\
\text { (III) } \mathrm{CH}_{4}+2 \mathrm{H}_{2} \mathrm{O} & \leftrightarrow \mathrm{CO}_{2}+4 \mathrm{H}_{2} & & &
\end{array}
$$

From Fig 1, the mass balance equations for $\mathrm{CH}_{4}, \mathrm{CO}, \mathrm{CO}_{2}, \mathrm{H}_{2}$ and $\mathrm{H}_{2} \mathrm{O}$ can be written as follows:

$$
\begin{aligned}
& N_{r} \dot{\mathcal{X}}_{1, r}=k \dot{N}_{o} \mathcal{X}_{1, a}-\dot{N}_{i n} \mathcal{X}_{1, r}+\mathcal{R}_{1, r}+\dot{N}_{f} \\
& N_{r} \dot{\mathcal{X}}_{2, r}=k \dot{N}_{o} \mathcal{X}_{2, a}-\dot{N}_{i n} \mathcal{X}_{2, r}+\mathcal{R}_{2, r}, \quad N_{r} \dot{\mathcal{X}}_{3, r}=k \dot{N}_{o} \mathcal{X}_{3, a}-\dot{N}_{i n} \mathcal{X}_{3, r}+\mathcal{R}_{3, r} \\
& N_{r} \dot{\mathcal{X}}_{4, r}=k \dot{N}_{o} \mathcal{X}_{4, a}-\dot{N}_{i n} \mathcal{X}_{4, r}+\mathcal{R}_{4, r}, \quad N_{r} \dot{\mathcal{X}}_{5, r}=k \dot{N}_{o} \mathcal{X}_{5, a}-\dot{N}_{i n} \mathcal{X}_{5, r}+\mathcal{R}_{5, r}
\end{aligned}
$$

where $N_{r}$ is the number of moles, and $\mathcal{R}_{j, r}, j=1,2, \cdots, 5$, represents the rate of formation of $\mathrm{CH}_{4}, \mathrm{CO}, \mathrm{CO}_{2}, \mathrm{H}_{2}$ and $\mathrm{H}_{2} \mathrm{O}$, in that order. The reformer inlet and exit flows shown in Fig 1 do not contain $N_{2}$ and $O_{2}$ (indices $j=6,7$ ). Hence $\mathcal{X}_{6, r}=\mathcal{X}_{7, r}=0$. From Eq.(11) and representing the rates of reactions I,

${ }_{140}$ II and III as $r_{I}, r_{I I}$ and $r_{I I I}$ respectively, we can express $\mathcal{R}_{j, r}, j=1,2, \cdots, 5$, as follows

$$
\mathbf{R}_{r}=\mathbf{r}^{T} \mathbf{M}, \quad \mathbf{R}_{r}^{T}=\left[\begin{array}{c}
\mathcal{R}_{1, r} \\
\mathcal{R}_{2, r} \\
\mathcal{R}_{3, r} \\
\mathcal{R}_{4, r} \\
\mathcal{R}_{5, r}
\end{array}\right], \quad \mathbf{r}=\left[\begin{array}{c}
r_{I} \\
r_{I I} \\
r_{I I I}
\end{array}\right], \quad \mathbf{M}^{T}=\left[\begin{array}{rrr}
-1 & 0 & -1 \\
1 & -1 & 0 \\
0 & 1 & 1 \\
3 & 1 & 4 \\
-1 & -1 & -2
\end{array}\right]
$$

Individual rows of $\mathbf{M}$ are populated by the coefficients of each species in each 
chemical reaction. Coefficients for reactants are entered as negative values indicating consumption, while positive values are used for products indicating generation. $\mathbf{M}$ is $m \times n$, where $n$ is the number of constituent gas species in the system, and $m$ is the number of distinct chemical reactions occurring within the SOFC system, excluding electrochemical reactions. Since $\mathbf{M}$ has a rank of 2 , therefore there are only two independent reaction rates among $\mathcal{R}_{j, r}$, $j=1,2, \cdots, 5$. Considering the rate of formation of $C H_{4}$ and $C O$ in the reformer to be independent, we can write

$$
\mathcal{R}_{3, r}=-\mathcal{R}_{1, r}-\mathcal{R}_{2, r}, \quad \mathcal{R}_{4, r}=-4 \mathcal{R}_{1, r}-\mathcal{R}_{2, r}, \quad \mathcal{R}_{5, r}=2 \mathcal{R}_{1, r}+\mathcal{R}_{2, r}
$$

and rewrite Eq.(2) as follows:

$$
\begin{aligned}
& N_{r} \dot{\mathcal{X}}_{1, r}=k \dot{N}_{o} \mathcal{X}_{1, a}-\dot{N}_{i n} \mathcal{X}_{1, r}+\mathcal{R}_{1, r}+\dot{N}_{f} \\
& N_{r} \dot{\mathcal{X}}_{2, r}=k \dot{N}_{o} \mathcal{X}_{2, a}-\dot{N}_{i n} \mathcal{X}_{2, r}+\mathcal{R}_{2, r} \\
& N_{r} \dot{\mathcal{X}}_{3, r}=k \dot{N}_{o} \mathcal{X}_{3, a}-\dot{N}_{i n} \mathcal{X}_{3, r}-\mathcal{R}_{1, r}-\mathcal{R}_{2, r} \\
& N_{r} \dot{\mathcal{X}}_{4, r}=k \dot{N}_{o} \mathcal{X}_{4, a}-\dot{N}_{i n} \mathcal{X}_{4, r}-4 \mathcal{R}_{1, r}-\mathcal{R}_{2, r} \\
& N_{r} \dot{\mathcal{X}}_{5, r}=k \dot{N}_{o} \mathcal{X}_{5, a}-\dot{N}_{i n} \mathcal{X}_{5, r}+2 \mathcal{R}_{1, r}+\mathcal{R}_{2, r}
\end{aligned}
$$

Mathematical models for the reaction rates $r_{I}, r_{I I}$ and $r_{I I I}$ are obtained from literature, [49]. However, these models are likely reformer and catalyst specific. The primary electrochemical process is steam generation from $H_{2}$, described by:

$$
\text { (IV) } \mathrm{H}_{2}+\mathrm{O}^{2-} \rightarrow \mathrm{H}_{2} \mathrm{O}+2 e .
$$

Simultaneous electrochemical conversion of $\mathrm{CO}$ to $\mathrm{CO}_{2}$ in the anode is also possible. However, this electro-chemical reaction is ignored since its reaction rate is much slower in presence of reactions II and IV, [50]. From Fig[1, the mass balance for $\mathrm{CH}_{4}, \mathrm{CO}, \mathrm{CO}_{2}, \mathrm{H}_{2}$ and $\mathrm{H}_{2} \mathrm{O}$ in the anode can be written as

$$
\begin{aligned}
& N_{a} \dot{\mathcal{X}}_{1, a}=-\dot{N}_{o} \mathcal{X}_{1, a}+\dot{N}_{i n} \mathcal{X}_{1, r}+\mathcal{R}_{1, a} \\
& N_{a} \dot{\mathcal{X}}_{2, a}=-\dot{N}_{o} \mathcal{X}_{2, a}+\dot{N}_{i n} \mathcal{X}_{2, r}+\mathcal{R}_{2, a} \\
& N_{a} \dot{\mathcal{X}}_{3, a}=-\dot{N}_{o} \mathcal{X}_{3, a}+\dot{N}_{i n} \mathcal{X}_{3, r}+\mathcal{R}_{3, a} \\
& N_{a} \dot{\mathcal{X}}_{4, a}=-\dot{N}_{o} \mathcal{X}_{4, a}+\dot{N}_{i n} \mathcal{X}_{4, r}+\mathcal{R}_{4, a}-r_{e} \\
& N_{a} \dot{\mathcal{X}}_{5, a}=-\dot{N}_{o} \mathcal{X}_{5, a}+\dot{N}_{i n} \mathcal{X}_{5, r}+\mathcal{R}_{5, a}+r_{e}
\end{aligned}
$$


where $N_{a}$ is the number of moles in the anode and $r_{e}$ is the rate of electrochem-

ical reaction given by

$$
r_{e}=\frac{i \mathcal{N}_{\text {cell }}}{n F},
$$

and $\mathcal{R}_{j, a}, j=1,2, \cdots, 5$, represents the rate of formation of $\mathrm{CH}_{4}, \mathrm{CO}, \mathrm{CO}_{2}, \mathrm{H}_{2}$ and $\mathrm{H}_{2} \mathrm{O}$. Since current $i$ can be measured, the rate of electrochemical reaction $r_{e}$ is considered known. As with the reformer, the anode inlet and exit flows also do not contain $\mathrm{O}_{2}$ and $N_{2}$. Therefore, $\mathcal{X}_{6, a}=\mathcal{X}_{7, a}=0$. From Eq.(6), we express $\mathcal{R}_{j, a}, j=1,2, \cdots, 5$, in terms of $r_{I}, r_{I I}$ and $r_{I I I}$ as follows

$$
\mathbf{R}_{a}=\mathbf{r}^{T} \mathbf{M}+r_{e}\left[\begin{array}{lllll}
0 & 0 & 0 & -1 & 1
\end{array}\right]
$$


$\mathbf{M}$ has a rank of 2 and $r_{e}$ is known, therefore there are only two independent reaction rates among $\mathcal{R}_{j, a}, j=1,2, \cdots, 5$. Considering $\mathcal{R}_{1, a}$ and $\mathcal{R}_{2, a}$ to be independent, we can write

$$
\mathcal{R}_{3, a}=-\mathcal{R}_{1, a}-\mathcal{R}_{2, a}, \mathcal{R}_{4, a}=-4 \mathcal{R}_{1, a}-\mathcal{R}_{2, a}-r_{e}, \mathcal{R}_{5, a}=2 \mathcal{R}_{1, a}+\mathcal{R}_{2, a}+r_{e}
$$

and rewrite Eq.(77) as

$$
\begin{aligned}
& N_{a} \dot{\mathcal{X}}_{1, a}=-\dot{N}_{o} \mathcal{X}_{1, a}+\dot{N}_{i n} \mathcal{X}_{1, r}+\mathcal{R}_{1, a} \\
& N_{a} \dot{\mathcal{X}}_{2, a}=-\dot{N}_{o} \mathcal{X}_{2, a}+\dot{N}_{i n} \mathcal{X}_{2, r}+\mathcal{R}_{2, a} \\
& N_{a} \dot{\mathcal{X}}_{3, a}=-\dot{N}_{o} \mathcal{X}_{3, a}+\dot{N}_{i n} \mathcal{X}_{3, r}-\mathcal{R}_{1, a}-\mathcal{R}_{2, a} \\
& N_{a} \dot{\mathcal{X}}_{4, a}=-\dot{N}_{o} \mathcal{X}_{4, a}+\dot{N}_{i n} \mathcal{X}_{4, r}-4 \mathcal{R}_{1, a}-\mathcal{R}_{2, a}-r_{e} \\
& N_{a} \dot{\mathcal{X}}_{5, a}=-\dot{N}_{o} \mathcal{X}_{5, a}+\dot{N}_{i n} \mathcal{X}_{5, r}+2 \mathcal{R}_{1, a}+\mathcal{R}_{2, a}+r_{e}
\end{aligned}
$$

\subsection{Characterization of Steady-State Utilization}

For SOFCs, fuel utilization $U$ is defined as the ratio of hydrogen consumption to the net effective available hydrogen in the anode. In the formulation of $U$, not only the available hydrogen but also the hydrogen that can be generated from other species through internal reforming are also accounted for, [15]. The definition of fuel utilization is, [15, 16, 17, 51]: 


$$
U \triangleq 1-\frac{\text { Potential hydrogen exiting the fuel cell anode }}{\text { Potential hydrogen entering the fuel cell anode }}
$$

Based on Eqs.(15) and (11), $U$ is formulated as:

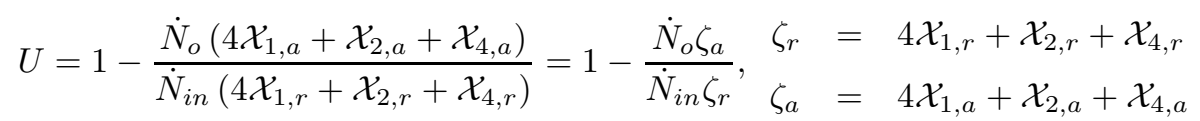

Equation (13) is based on the internal reforming capability of the anode, where one $\mathrm{CH}_{4}$ and one $\mathrm{CO}$ molecule can yield upto four molecules and one molecule of $\mathrm{H}_{2}$, respectively. This is evident from Eq.(11). Using Eqs.(11), (13) and (5), $\zeta_{r}$ and $\zeta_{a}$ are expressed as:

$$
\dot{\zeta}_{r}=\frac{-\dot{N}_{i n}}{N_{r}} \zeta_{r}+\frac{k \dot{N}_{o}}{N_{r}} \zeta_{a}+\frac{4 \dot{N}_{f}}{N_{r}} \quad \dot{\zeta}_{a}=\frac{\dot{N}_{i n}}{N_{a}} \zeta_{r}-\frac{\dot{N}_{o}}{N_{a}} \zeta_{a}-\frac{i \mathcal{N}_{c e l l}}{n F N_{a}}
$$

It is interesting to note here that Eq.(14) is devoid of the reaction rates $\mathcal{R}_{1, r}$, $\mathcal{R}_{2, r}, \mathcal{R}_{1, a}$, and $\mathcal{R}_{2, a}$. This is advantageous, but Eq.(14) is nonetheless nonlinear since $\dot{N}_{i n}, \dot{N}_{o}, N_{r}, N_{a}$ are nonlinear functions of mole fractions, temperatures and pressures, [37]. From Eqs.(13) and (14), upon setting $\dot{\zeta}_{r}=\dot{\zeta}_{a}=0$, we obtain the following expression for steady-state utilization, $U_{s s}$ :

$$
U_{s s}=(1-k) /\left[\left(4 n F \dot{N}_{f} / i \mathcal{N}_{c e l l}\right)-k\right]
$$

Note that Eq. (15) can be used to exactly predict the steady-state fuel utilization for any given set of inputs $i$ and $\dot{N}_{f}$ for known and constant recirculation $k$. We term this as an invariant property of $U$ since it is independent of temperatures, pressures, and reaction rates.

\subsection{Characterization of Steam-To-Carbon-Balance}

Steam-to-carbon-ratio $(S T C R)$ is a critical variable in steam-reformers. It indicates the availability of steam for fuel reforming. A minimum STCR, that allows stoichiometric combination of steam and carbon, is necessary. For steam 
imately 2. A mixture deficient in steam causes catalyst deactivation through carbon deposition on the catalyst surfaces, [47, 52], and therefore must be prevented. $S T C R$ is defined as follows:

$$
S T C R \triangleq \frac{\text { Net amount of Steam at the Inlet of SR }}{\text { Net amount of Carbon Atoms at the Inlet of SR }}
$$

Referring to Fig 1 and Eq.(16), $S T C R$ is formulated as

$$
S T C R=k \dot{N}_{o} \mathcal{X}_{5, a} /\left(\dot{N}_{f}+k \dot{N}_{o} \mathcal{X}_{1, a}+k \dot{N}_{o} \mathcal{X}_{2, a}\right)
$$

200 molecules to that of carbon atoms at the inlet of the reformer. From Eqs. (13) and (14), it can be verified that unlike $U_{s s}$, a steady-state invariant relation for $S T C R$ is not possible. In section 3 , we explore the reason behind this. In one of our earlier works, [37], we defined a new variable called steam-to-carbon-balance $(S T C B)$, which conveys similar information as $S T C R$ and exhibits an invariant property, akin to $U$. It is defined as follows:

$$
\begin{aligned}
S T C B & \triangleq \text { Excess steam at the reformer inlet } \\
& \triangleq k \dot{N}_{o} \mathcal{X}_{5, a}-\left(2 \dot{N}_{f}+2 k \dot{N}_{o} \mathcal{X}_{1, a}+k \dot{N}_{o} \mathcal{X}_{2, a}\right) \\
& =k \dot{N}_{o}\left(\mathcal{X}_{5, a}-2 \mathcal{X}_{1, a}-\mathcal{X}_{2, a}\right)-2 \dot{N}_{f}
\end{aligned}
$$

The variable $S T C B$ represents potential excess steam in the inlet flow into the reformer, assuming stoichiometric consumption of steam by fuel and recirculated flow through steam-reforming, as per Eq.(1). It is evident that the stoichiometric quantity of steam required for reforming 1 mole each of $\mathrm{CH}_{4}$ and $\mathrm{CO}$ is 2 moles and 1 mole, respectively. Similar to $S T C R$, all the calculations for the $S T C B$ are based on reformer inlet conditions. It is clear that $S T C B>0$ is desirable to prevent carbon deposition, [37]. Similar to discussion in section (2.3), we rewrite Eq.(18) using the following coordinate transformations:

$$
\begin{aligned}
S T C B=k \dot{N}_{o} \xi_{a}-2 \dot{N}_{f}, \quad & \xi_{r}=\mathcal{X}_{5, r}-2 \mathcal{X}_{1, r}-\mathcal{X}_{2, r} \\
\xi_{a} & =\mathcal{X}_{5, a}-2 \mathcal{X}_{1, a}-\mathcal{X}_{2, a}
\end{aligned}
$$




$$
N_{r} \dot{\xi}_{r}=-\dot{N}_{i n} \xi_{r}+k \dot{N}_{o} \xi_{a}-2 \dot{N}_{f}, \quad N_{a} \dot{\xi}_{a}=\dot{N}_{i n} \xi_{r}-\dot{N}_{o} \xi_{a}+i \mathcal{N}_{c e l l} / n F
$$

From Eq. (20), we obtain the following steady-state expression for $S T C B$ which is also invariant with respect to temperatures, pressures, and reaction rates:

$$
S T C B_{s s}=\frac{1}{1-k}\left(-2 \dot{N}_{f}+\frac{k i \mathcal{N}_{\text {cell }}}{n F}\right) \text {. }
$$

In the next section, we will present a generalized mathematical basis behind invariant properties in SOFC systems and develop an analytical approach for deriving the same.

\section{Abstraction of Invariant Properties}

\subsection{General SOFC System}

We now generalize the analysis presented in section 2 using a generic SOFC system, illustrated in Fig. 2. The inlet molar fuel flow $\dot{N}_{f}$ to the reformer is assumed to consist entirely of a hydrocarbon whose chemical composition can be expressed in the form $\mathrm{C}_{a} \mathrm{H}_{2 b} \mathrm{O}_{d}$, where $a, b$, and $d$ are non-negative integers and $a \neq 0$. Steam is supplied to the Steam Reformer from either a recirculated flow $k \dot{N}_{o}$, or from an external steam supply $\dot{N}_{s t}$. The external steam supply is optional and is added to further generalize the analysis. All other details of the system are similar to that of Fig 1 in section 2.1

We start this study by assuming that only $\mathrm{H}_{2}$ reacts to produce electricity in the anode. The term "fuel" refers to either hydrogen molecules, or hydrocarbons with the potential of being reformed to produce hydrogen molecules. The hydrogen thus obtained or can be obtained will henceforth be referred to as potential hydrogen. The gas mixture entering SOFC anode also contains CO that can undergo parallel electrochemical oxidation. We will show in section 3.4 that the proposed approach can be extended, without any loss of generality, to situations where such parallel electrochemical oxidation is accounted for. 


\subsection{Potential Hydrogen - Formulating Vector $\mathbf{P}$}

240

Hydrogen. We formulate it as a vector $\mathbf{P}$ whose entries are the maximum hydrogen producing capability of each species of the gas mixture flowing through the reformer and anode. For the methane based system discussed in section 2. with steam reforming reactions in Eq.(11), potential hydrogen can be formu245 lated as $\mathbf{P}=\left[\begin{array}{llll}4 & 1 & 0 & 1\end{array}\right]^{T}$. Referring to section 2.3 and the discussion around Eqs.(12) and (13), we observe that $\dot{N}_{o}\left(4 \mathcal{X}_{1, a}+\mathcal{X}_{2, a}+\mathcal{X}_{4, a}\right)=\dot{N}_{o} \mathbf{P}^{T} \mathbf{X}_{a}$ and $\dot{N}_{i n}\left(4 \mathcal{X}_{1, r}+\mathcal{X}_{2, r}+\mathcal{X}_{4, r}\right)=\dot{N}_{i n} \mathbf{P}^{T} \mathbf{X}_{r}$. Here, $\mathbf{X}_{a}$ and $\mathbf{X}_{r}$ are vectors representing the mole fractions of each gas species in the anode exhaust and inlet flows respectively. Extending this formulation to the generalized SOFC system of Fig,2, we write

$$
U=1-\left(\dot{N}_{o} \mathbf{P}^{T} \mathbf{X}_{a}\right) /\left(\dot{N}_{i n} \mathbf{P}^{T} \mathbf{X}_{r}\right)
$$

The flow rates $\dot{N}_{o}$ and $\dot{N}_{i n}$ are shown in Fig 2. It is evident that the $n \times 1$ vector $\mathbf{P}$ must be determined in a way such that it accurately relates the maximum potential hydrogen of each species and we must show the invariance to internal reaction rates when steady-state utilization is calculated using Eq.(22). We next make the following observation: The chemical reactions in steam reforming, such as those shown in Eq.(1), do not change the total potential hydrogen extractable from the gas mixture, they only change the form from higher hydrocarbons to lower hydrocarbons and hydrogen molecules. Potential hydrogen changes only through electrochemical reactions. This can be mathematically formulated using the matrix definitions in Eq.(3) as the condition $\mathbf{r}^{T} \mathbf{M P}=0$. However, since reaction rates in $\mathbf{r}$ are functions of time, varying with partial pressures, temperature, and potentially several other parameters, it follows that:

$$
\mathbf{R}_{r} \mathbf{P}=\mathbf{r}^{T} \mathbf{M P}=0 \quad \Rightarrow \quad \mathbf{M P}=[0] .
$$

During steam reforming of hydrocarbons, a large number of reactions may be occurring simultaneously including decomposition, methanation, the water-gas 


\subsection{Steady-State Fuel Utilization $U$}

Equation (22) is particularly useful when coupled with conservation of mass equations for the SOFC system in Fig,2, The conservation of mass for an in-

For a hydrocarbon fuel as defined in section 3.1. Eq. (25) is a generic complete steam reforming reaction. It can be observed, that including the coefficients of this reaction for each potential fuel as the rows in $\mathbf{L}$ will create a linearly independent subset of M. Furthermore, Eq.(25) indicates that the maximum number of hydrogen molecules to be obtained from a fuel of type $\mathrm{C}_{a} \mathrm{H}_{2 b} \mathrm{O}_{d}$, from an $\mathrm{H}_{2}$, and from a non-fuel molecule in the flow that does not conform with the definition of fuel (i.e. $\mathrm{C}_{a} \mathrm{H}_{2 b} \mathrm{O}_{d}$, with $a \neq 0$ ), through steam reforming are,

$$
p_{\text {fuel }}=(2 a+b-d) \geq 0, \quad p_{H_{2}}=1, \quad p_{\text {non-fuel }}=0
$$

Thus, for a gas mixture containing $\mathrm{C}_{a} \mathrm{H}_{2 b} \mathrm{O}_{d}, \mathrm{CO}_{2}, \mathrm{H}_{2}, \mathrm{H}_{2} \mathrm{O}$, the corresponding

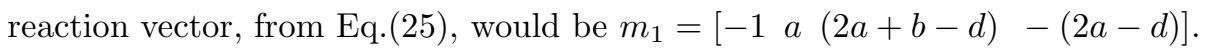
For the same gas mixture, the Potential Hydrogen vector, from Eq.(26), would be $\mathbf{P}=\left[(2 a+b-d) \quad \begin{array}{lll}0 & 1 & 0\end{array}\right]^{T}$, and it can be observed that $m_{1} \mathbf{P}=0$. While the idea of maximum extractable hydrogen through reforming appears in some works, [40, 53], the vector formulation of $U$ in Eq.(22) is novel. Next we will show that this vector formulation lends to derivation of invariant properties.

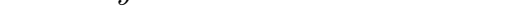
equations for the SOFC system in Fig, The conservation of mass for an in- 
dividual species in the reformer control volume follows from generalization of

$$
\frac{d}{d t}\left(N_{r} \mathcal{X}_{j, r}\right)=k \dot{N}_{o} \mathcal{X}_{j, a}+\dot{N}_{f} \mathcal{X}_{j, f}+\dot{N}_{s t} \mathcal{X}_{j, s t}-\dot{N}_{i n} \mathcal{X}_{j, r}+\mathcal{R}_{j, r}
$$

where, $j=1,2,3, \ldots$, represents individual species in the gas flow. $\mathcal{X}_{j, f}$ and $\mathcal{X}_{j, s t}$ represent the molar concentrations of the $j^{\text {th }}$ species in the fuel flow $\dot{N}_{f}$ and steam flow $\dot{N}_{s t}$ respectively. $\mathcal{R}_{j, r}$ is the net rate of formation of species $j$ due to all chemical reactions in the reformer. The conservation of mass equation for the gas mixture is obtained by combining the individual equations of Eq.(27) in a matrix form,

$$
\frac{d}{d t}\left(N_{r} \mathbf{X}_{r}\right)=k \dot{N}_{o} \mathbf{X}_{a}+\dot{N}_{f} \mathbf{X}_{f}+\dot{N}_{s t} \mathbf{X}_{s t}-\dot{N}_{i n} \mathbf{X}_{r}+\mathbf{R}_{r}^{T}
$$

where, $\mathbf{X}_{r}=\left[\begin{array}{llll}X_{1, r} & X_{2, r} & X_{3, r} & \cdots\end{array}\right]^{T}, \mathbf{X}_{a}=\left[\begin{array}{llll}X_{1, a} & X_{2, a} & X_{3, a} & \cdots\end{array}\right]^{T}, \mathbf{X}_{f}=\left[\begin{array}{lll}X_{1, f} & \end{array}\right.$ $\left.\begin{array}{llll}X_{2, f} & X_{3, f} & \cdots\end{array}\right]^{T}, \mathbf{X}_{s t}=\left[\begin{array}{llll}X_{1, s t} & X_{2, s t} & X_{3, s t} & \cdots\end{array}\right]^{T}$, and $\mathbf{R}_{r}=\left[\begin{array}{llll}\mathcal{R}_{1, r} & \mathcal{R}_{2, r} & \mathcal{R}_{3, r} & \cdots\end{array}\right]$. It is noted that the indices $1,2,3, \ldots$, represent individual species in the gas flow and hence the same sequence is used to present species molar fractions in vectors $\mathbf{X}_{r}, \mathbf{X}_{a}, \mathbf{X}_{f}$ and $\mathbf{X}_{s t}$. The mass balance of the potential hydrogen in each reforming reaction can be found by pre-multiplying Eq.(28) with $\mathbf{P}^{T}$. This results in an equation for the conservation of mass of potential hydrogen as follows,

$$
\dot{N}_{r} \mathbf{P}^{T} \mathbf{X}_{r}+N_{r} \mathbf{P}^{T} \dot{\mathbf{X}}_{r}=k \dot{N}_{o} \mathbf{P}^{T} \mathbf{X}_{a}+\dot{N}_{f} \mathbf{P}^{T} \mathbf{X}_{f}+\dot{N}_{s t} \mathbf{P}^{T} \mathbf{X}_{s t}-\dot{N}_{i n} \mathbf{P}^{T} \mathbf{X}_{r}+\mathbf{P}^{T} \mathbf{R}_{r}^{T}
$$

Under steady-state conditions, the left hand side of Eq.(29) goes to zero. In addition, applying the conservation of hydrogen condition of Eq.(23), we get

$$
0=k \dot{N}_{o} \mathbf{P}^{T} \mathbf{X}_{a}+\dot{N}_{f} \mathbf{P}^{T} \mathbf{X}_{f}+\dot{N}_{s t} \mathbf{P}^{T} \mathbf{X}_{s t}-\dot{N}_{i n} \mathbf{P}^{T} \mathbf{X}_{r}
$$

Referring to Fig 2, the pre-reformed fuel $\dot{N}_{f}$ with species concentrations $\mathbf{X}_{f}$ is considered known, the steam input $\dot{N}_{s t}$ has concentrations $\mathbf{X}_{s t}$ where the entries of this vector are zero excepting for the entry corresponding to concentration of steam which is 1 , and $k \dot{N}_{o}$ with concentrations $\mathbf{X}_{a}$. In Eq.(30), since 
the steam flow does not contain any potential hydrogen, therefore $\mathbf{P}^{T} \mathbf{X}_{s t}=0$. This simplifies Eq.(30) to,

$$
0=\dot{N}_{f} \mathbf{P}^{T} \mathbf{X}_{f}+k \dot{N}_{o} \mathbf{P}^{T} \mathbf{X}_{a}-\dot{N}_{i n} \mathbf{P}^{T} \mathbf{X}_{r}
$$

We next apply the same mass balance to the anode. A parallel of Eq.(27) can be written as follows:

$$
\frac{d}{d t}\left(N_{a} \mathcal{X}_{j, a}\right)=\dot{N}_{i n} \mathcal{X}_{j, r}-\dot{N}_{o} \mathcal{X}_{j, a}+\mathcal{R}_{j, a}+\mathcal{R}_{j, e}
$$

where $\mathcal{R}_{j, a}$ and $\mathcal{R}_{j, e}$ represent the net rate of formation of the $j^{\text {th }}$ species due to reforming reactions and electrochemical reactions respectively in the anode. As before, the conservation of mass equation for the mixture is obtained by combining the individual equations of Eq.(32) in a matrix form,

$$
\frac{d}{d t}\left(N_{a} \mathbf{X}_{a}\right)=\dot{N}_{i n} \mathbf{X}_{r}-\dot{N}_{o} \mathbf{X}_{a}+\mathbf{R}_{a}^{T}+\mathbf{R}_{e}^{T}
$$

where, $\mathbf{R}_{a}=\left[\begin{array}{llll}\mathcal{R}_{1, a} & \mathcal{R}_{2, a} & \mathcal{R}_{3, a} \cdots\end{array}\right]$, and $\mathbf{R}_{e}=\left[\begin{array}{lll}\mathcal{R}_{1, e} & \mathcal{R}_{2, e} & \mathcal{R}_{3, e} \cdots\end{array}\right]$. Upon imposing steady-state conditions, pre-multiplying with $\mathbf{P}^{T}$, and observing that $\mathbf{P}^{T} \mathbf{R}_{a}^{T}=0$ due to conservation of potential hydrogen, Eq. (33) thus reduces to

$$
0=\dot{N}_{i n} \mathbf{P}^{T} \mathbf{X}_{r}-\dot{N}_{o} \mathbf{P}^{T} \mathbf{X}_{a}+\mathbf{P}^{T} \mathbf{R}_{e}^{T}
$$

We finally note that since the electrochemical reaction Eq.(6) proceeds at the rate given by Eq.(8), and $p_{H_{2}}=1$ and $p_{H_{2} O}=0$ as per Eq.(26), therefore $\mathbf{P}^{T} \mathbf{R}_{e}^{T}=p_{H_{2}}\left(-r_{e}\right)+p_{H_{2} O}\left(r_{e}\right)=-r_{e}$. Thus, Eq.(34) is simplified to

$$
0=\dot{N}_{i n} \mathbf{P}^{T} \mathbf{X}_{r}-\dot{N}_{o} \mathbf{P}^{T} \mathbf{X}_{a}-r_{e}
$$

From Eqs.(22), (31) and (35), the steady-state utilization $U_{s s}$ is obtained as

$$
U_{s s}=\frac{1-k}{\left(n F \dot{N}_{f} \mathbf{P}^{T} \mathbf{X}_{f} / i \mathcal{N}_{c e l l}\right)-k}
$$

325 Note that in Eq.(36), $i$ and $\dot{N}_{f}$ are inputs and $\mathcal{N}_{\text {cell }}, n, F, k$ and $\mathbf{X}_{f}$ are known quantities. Hence, by constructing $\mathbf{P}$ using the approach shown in section 3.2 one can predict $U_{s s}$ for any set of input conditions for an SOFC system without 
knowledge of the rates of reforming reactions, internal flow rates, temperatures and pressures.

\subsection{Parallel Electrochemical Oxidation of $\mathrm{CO}$}

So far in our analysis we have assumed that the only electrochemical reaction in the anode is that of $\mathrm{H}_{2}$, Eq.(6). In this section we extend our analysis to the scenario where parallel electrochemical oxidation of CO, namely

$$
\mathrm{CO}+\mathrm{O}^{2-} \rightarrow \mathrm{CO}_{2}+2 e,
$$

is also considered. We assume the individual rates of the two electrochemical reactions $r_{e, H_{2}}$ and $r_{e, C O}$ to be unknown. However, the net rate of electrochemical reactions, $r_{e}=r_{e, H_{2}}+r_{e, C O}$ is still determined by the total current $i$ and hence will satisfy Eq.(8). We also note from Eq.(26), that $p_{H_{2}}=p_{C O}=1$ and $p_{\mathrm{H}_{2} \mathrm{O}}=p_{\mathrm{CO}_{2}}=0$. Note that $p_{\mathrm{CO}}=1$ and $p_{\mathrm{CO}_{2}}=0$ can be obtained from the expression of $p_{\text {fuel }}$ in Eq.(26). Thus, referring back to Eq.(34), the term $\mathbf{P}^{T} \mathbf{R}_{e}^{T}$ again simplifies to

$$
\begin{aligned}
\mathbf{P}^{T} \mathbf{R}_{e}^{T} & =p_{H_{2}}\left(-r_{e, H_{2}}\right)+p_{H_{2} O}\left(r_{e, H_{2}}\right)+p_{C O}\left(-r_{e, C O}\right)+p_{C O_{2}}\left(r_{e, C O}\right) \\
& =-r_{e, H_{2}}-r_{e, C O}=-r_{e} .
\end{aligned}
$$

Thus the mass balance equation of the anode, namely Eq.(31), remains unchanged. The definition of $U$ in Eq.(12) remains the same and knowledge of the individual rates $r_{e, H_{2}}$ and $r_{e, C O}$ are not needed in formulating $U_{s s}$. Hence, the general form of the invariant property in Eq.(36) remains unchanged.

\subsection{Steady-State Steam-to-Carbon-Balance (STCB)}

In this section we generalize the discussion presented in section 2.4 on STCB for a specific SOFC system. We recall that between the steady-state steamto-carbon-ratio $S T C R$ and $S T C B$, the former did not display an invariant property while the latter did. In light of the generalized analysis of $U$ in section 350 3.3. we conclude that this is because the definition of $S T C R$ does not involve 
a conserved variable, while the definition of $S T C B$ does. $S T C B$, as defined in Eq.(18), represents the minimum extra steam at the reformer inlet assuming complete stoichiometric consumption of steam by fuel species in the reformer. Hence, it is a conserved variable, that is independent of the rates of reactions.

Similar to the discussion in section 3.2, we formulate a vector, namely potential steam $\mathbf{Q}$, whose entries are the maximum steam generating capability of each species in the gas mixture. For the methane based system discussed in section 2, with steam reforming reactions in Eq.(1), it can be formulated as $\mathbf{Q}=\left[\begin{array}{lllll}-2 & -1 & 0 & 0 & 1\end{array}\right]^{T}$. The total potential steam for this system can be verified as a conserved variable, by noting from Eq.(3) that

$$
\mathbf{R}_{r} \mathbf{Q}=\mathbf{r}^{T} \mathbf{M} \mathbf{Q}=0 .
$$

Referring to section 2.4 and the discussion around Eqs.(19) and (20), we observe that $\dot{N}_{o}\left(-2 \mathcal{X}_{1, a}-\mathcal{X}_{2, a}+\mathcal{X}_{5, a}\right)=\dot{N}_{o} \mathbf{Q}^{T} \mathbf{X}_{a}$ and $\dot{N}_{i n}\left(-2 \mathcal{X}_{1, r}-\mathcal{X}_{2, r}+\mathcal{X}_{5, r}\right)=$ $\dot{N}_{i n} \mathbf{Q}^{T} \mathbf{X}_{r}$.

For the general SOFC system of Fig 2 with fuel $\mathrm{C}_{a} \mathrm{H}_{2 b} \mathrm{O}_{d}$ and the steam reforming reaction Eq.(25), the individual entries of the $\mathbf{Q}$ for different species would be

$$
q_{\text {fuel }}=-(2 a-d) \leq 0, \quad q_{H_{2} O}=1, \quad q_{\text {non-fuel }}=q_{H_{2}}=0 .
$$

Thus, for a gas mixture containing $\mathrm{C}_{a} \mathrm{H}_{2 b} \mathrm{O}_{d}, \mathrm{CO}_{2}, \mathrm{H}_{2}, \mathrm{H}_{2} \mathrm{O}$, the corresponding

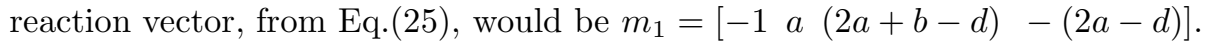
For the same gas mixture, the Potential Steam vector, from Eq.(39), would be 370 $\mathbf{Q}=\left[\begin{array}{llll}-(2 a-d) & 0 & 0 & 1\end{array}\right]^{T}$, and it can be observed that $m_{1} \mathbf{Q}=0$. Referring to the flow rates shown in Fig 2 STCB can be formulated as,

$S T C B=k \dot{N}_{o} \mathbf{Q}^{T} \mathbf{X}_{a}+\dot{N}_{s t} \mathbf{Q}^{T} \mathbf{X}_{s t}+\dot{N}_{f} \mathbf{Q}^{T} \mathbf{X}_{f}=k \dot{N}_{o} \mathbf{Q}^{T} \mathbf{X}_{a}+\dot{N}_{s t}+\dot{N}_{f} \mathbf{Q}^{T} \mathbf{X}_{f}$

The simplification $\mathbf{Q}^{T} \mathbf{X}_{s t}=1$ is valid since $q_{H 2 O}=1$ and in $\mathbf{X}_{s t}$ all entries are zero except that of $\mathrm{H}_{2} \mathrm{O}$ which is 1 . Similar to the discussion in section 
3.3. we attempt to obtain the steady-state $S T C B$ from the mass balance of

the reformer and anode volumes. Pre-multiplying the reformer mass balance equation in Eq.(28) with $\mathbf{Q}^{T}$ and imposing steady-state condition we get

$$
0=k \dot{N}_{o} \mathbf{Q}^{T} \mathbf{X}_{a}+\dot{N}_{f} \mathbf{Q}^{T} \mathbf{X}_{f}+\dot{N}_{s t} \mathbf{Q}^{T} \mathbf{X}_{s t}-\dot{N}_{i n} \mathbf{Q}^{T} \mathbf{X}_{r}+\mathbf{Q}^{T} \mathbf{R}_{r}^{T}
$$

Using Eq.(38), Eq.(41) simplifies to

$$
0=k \dot{N}_{o} \mathbf{Q}^{T} \mathbf{X}_{a}+\dot{N}_{f} \mathbf{Q}^{T} \mathbf{X}_{f}+\dot{N}_{s t}-\dot{N}_{i n} \mathbf{Q}^{T} \mathbf{X}_{r}
$$

Next, the mass balance equation of anode in Eq. (33) is pre-multiplied with $\mathbf{Q}^{T}$, steady-state condition is imposed, and observing that $\mathbf{Q}^{T} \mathbf{R}_{a}^{T}=0$ due to conservation of potential steam, we obtain

$$
0=\dot{N}_{i n} \mathbf{Q}^{T} \mathbf{X}_{r}-\dot{N}_{o} \mathbf{Q}^{T} \mathbf{X}_{a}+\mathbf{Q}^{T} \mathbf{R}_{e}^{T}
$$

Note that the electrochemical reaction Eq. (6) proceeds at the rate given by Eq.(8), and $q_{H_{2}}=0$ and $q_{H_{2} O}=1$ as per Eq.(39). Therefore, $\mathbf{Q}^{T} \mathbf{R}_{e}^{T}=$ $q_{H_{2}}\left(-r_{e}\right)+q_{H_{2} O}\left(r_{e}\right)=r_{e}$. Thus, Eq. (43) is simplified to

$$
0=\dot{N}_{i n} \mathbf{Q}^{T} \mathbf{X}_{r}-\dot{N}_{o} \mathbf{Q}^{T} \mathbf{X}_{a}+r_{e}
$$

From Eqs.(8), (40), (42), (44), the steady-state $S T C B$ is expressed as

$$
S T C B_{s s}=\frac{1}{1-k}\left[\dot{N}_{f} \mathbf{Q}^{T} \mathbf{X}_{f}+\dot{N}_{s t}+\frac{k i \mathcal{N}_{c e l l}}{n F}\right]
$$

${ }_{385}$ Note that in Eq. (45), $i, \dot{N}_{f}, \dot{N}_{s t}$ are inputs and $\mathcal{N}_{\text {cell }}, n, F, k$ and $\mathbf{X}_{f}$ are known quantities. Hence, by constructing $\mathbf{Q}, S T C B_{s s}$ can be predicted without knowledge of the rates of reforming reactions, internal flow rates, temperatures and pressures. 


\section{Examples}

390 4.1. Mixture of Methane $\left(\mathrm{CH}_{4}\right)$ and Carbon Monoxide (CO)

We first consider a mixture of methane and carbon monoxide as the fuel. By assigning index 1 to $\mathrm{CH}_{4}$, and 2 to $\mathrm{CO}$, we define $\mathbf{X}_{f}$ for the mixture as

$$
\mathbf{X}_{f}^{T}=\left[\begin{array}{lllll}
\mathcal{X}_{1, f} & \mathcal{X}_{2, f} & 0 & \cdots & 0
\end{array}\right], \quad \mathcal{X}_{1, f}+\mathcal{X}_{2, f}=1
$$

With this mixed fuel, the steam-reforming reactions are the same as with pure methane. Therefore Eqs.(1) and (3) are still valid, and Eqs.(25) and (26) yield ${ }_{395} p_{1}=4, p_{2}=1$. The reformed gas mixture will consist of species $\mathrm{CH}_{4}, \mathrm{CO}$, $\mathrm{CO}_{2}, \mathrm{H}_{2}, \mathrm{H}_{2} \mathrm{O}$. The vector $\mathbf{P}$, with species represented in this order, will be $\mathbf{P}^{T}=\left[\begin{array}{lllll}4 & 1 & 0 & 1 & 0\end{array}\right]$. Therefore, by using Eq.(36), we have

$$
U_{s s}=\frac{1-k}{\left[\left(4 \mathcal{X}_{1, f}+\mathcal{X}_{2, f}\right) n F \dot{N}_{f} / i \mathcal{N}_{c e l l}\right]-k}=\frac{1-k}{\left[\left(1+3 \mathcal{X}_{1, f}\right) n F \dot{N}_{f} / i \mathcal{N}_{c e l l}\right]-k}
$$

Similarly, from Eq.(39), $\mathbf{Q}$ is obtained as $\mathbf{Q}^{T}=\left[\begin{array}{lllll}-2 & -1 & 0 & 0 & 1\end{array}\right]$. Note that both $\mathbf{P}$ and $\mathbf{Q}$ remain the same as those for both pure Methane because the reforming 400 reactions remain the same. By using Eq (45), steady-state $S T C B_{\text {ss }}$ for steam reforming with a mixture of $\mathrm{CH}_{4}$ and $\mathrm{CO}$ will be

$$
\begin{aligned}
S T C B_{s s} & =\frac{1}{1-k}\left[\dot{N}_{f}\left(-2 X_{1, f}-X_{2, f}\right)+\frac{k i \mathcal{N}_{\text {cell }}}{n F}\right] \\
& =\frac{1}{1-k}\left[\dot{N}_{f}\left(-X_{1, f}-1\right)+\frac{k i \mathcal{N}_{\text {cell }}}{n F}\right]
\end{aligned}
$$

\subsection{Ethanol $\left(\mathrm{C}_{2} \mathrm{H}_{5} \mathrm{OH}\right)$}

For pure ethanol, in generating $\mathbf{X}$ we assign index 1 to $\mathrm{C}_{2} \mathrm{H}_{5} \mathrm{OH}$ and treat all other species formed through steam reforming as unknown. Moreover, $\mathbf{X}_{f}^{T}=$ ${ }_{405} \quad\left[\begin{array}{lllll}1 & 0 & 0 & \cdots & 0\end{array}\right]$. From Eqs.(25) and (26), we have $p_{1}=6$, implying, $\mathbf{P}^{T}=$ $\left[\begin{array}{lllll}6 & p_{2} & p_{3} & \cdots & p_{n}\end{array}\right]$. Thus, from Eq. (36) we have

$$
U_{s s}=\frac{1-k}{\left(6 n F \dot{N}_{f} / i \mathcal{N}_{c e l l}\right)-k}
$$


Similarly, from Eqs.(25) and (39), we have $q_{1}=-(2 a-d)=-3$, implying $\mathbf{Q}^{T}=\left[\begin{array}{lllll}-3 & q_{2} & q_{3} & \cdots & q_{n}\end{array}\right]$. Thus, from Eq.(45) we have:

$$
S T C B_{s s}=\frac{1}{1-k}\left[-3 \dot{N}_{f}+\frac{k i \mathcal{N}_{\text {cell }}}{n F}\right]
$$

In verifying the validity of the above equations, we consider two different expressions for $U_{s s}$ and $S T C B_{s s}$ for each case are found to be the same.

\subsubsection{Reaction Scheme I}

The first set of reactions, [55], are as follows:

$$
\begin{gathered}
\mathrm{C}_{2} \mathrm{H}_{5} \mathrm{OH}+\mathrm{H}_{2} \mathrm{O} \leftrightarrow 2 \mathrm{CO}+4 \mathrm{H}_{2}, \mathrm{C}_{2} \mathrm{H}_{5} \mathrm{OH}+3 \mathrm{H}_{2} \mathrm{O} \leftrightarrow 2 \mathrm{CO}_{2}+6 \mathrm{H}_{2}, \\
\mathrm{CO}+\mathrm{H}_{2} \mathrm{O} \leftrightarrow \mathrm{CO}_{2}+\mathrm{H}_{2} .
\end{gathered}
$$

Five species participate in the above reactions, $\mathrm{C}_{2} \mathrm{H}_{5} \mathrm{OH}, \mathrm{CO}, \mathrm{CO}_{2}, \mathrm{H}_{2}$, and

$\mathrm{H}_{2} \mathrm{O}$, which will be represented by $j=1,2,3,4$ and 5 respectively. The $\mathbf{M}$ matrix is constructed from the coefficients of Eq.(49).

$$
\mathbf{M}=\left[\begin{array}{rrrrr}
-1 & 2 & 0 & 4 & -1 \\
-1 & 0 & 2 & 6 & -3 \\
0 & -1 & 1 & 1 & -1
\end{array}\right]
$$

The coefficients $(a, b, d)$ for the species are as follows: $(2,3,1)$ for $j=1,(1,0,1)$ for $j=2,(1,0,2)$ for $j=3,(0,1,0)$ for $j=4$, and $(0,1,1)$ for $j=5$. The complete vector $\mathbf{P}$ can therefore be formulated using Eq.(26) as $\mathbf{P}^{T}=$

${ }_{420}\left[\begin{array}{lllll}6 & 1 & 0 & 1 & 0\end{array}\right]$. From section 3.2 and Eq.(25) the following two independent reactions can be constructed:

$$
\mathrm{C}_{2} \mathrm{H}_{5} \mathrm{OH}+3 \mathrm{H}_{2} \mathrm{O} \leftrightarrow 2 \mathrm{CO}_{2}+6 \mathrm{H}_{2}, \quad \mathrm{CO}+\mathrm{H}_{2} \mathrm{O} \leftrightarrow \mathrm{CO}_{2}+\mathrm{H}_{2} .
$$

Thus, $\mathbf{L}$ can be formulated as:

$$
\mathbf{L}=\left[\begin{array}{ccccc}
-1 & 0 & 2 & 6 & -3 \\
0 & -1 & 1 & 1 & -1
\end{array}\right]
$$


The matrices M, L and $\mathbf{P}$ satisfy Eqs.(23) and (24). Finally, for ethanol as fuel, $\mathbf{X}_{f}^{T}=\left[\begin{array}{lllll}1 & 0 & 0 & 0 & 0\end{array}\right]$. Substituting for $\mathbf{P}^{T}$ and $\mathbf{X}_{f}^{T}$ from above into Eq.(36) we have the same relationship as in Eq.(47). Similarly, from Eqs.(25) and (39), the complete $\mathbf{Q}$ matrix for ethanol would be $\mathbf{Q}^{T}=\left[\begin{array}{lllll}-3 & -1 & 0 & 0 & 1\end{array}\right]$. It can be verified that $\mathbf{Q}$ and $\mathbf{M}$ satisfy Eq.(38). Thus, the complete $\mathbf{Q}$ matrix, and $\mathbf{X}_{f}^{T}$ will give the same relationship as in Eq.(48), upon substituting in Eq.(45).

\subsubsection{Reaction Scheme II}

A second set of possible reforming reactions for ethanol, [56], was chosen for analysis:

$$
\begin{gathered}
\mathrm{C}_{2} \mathrm{H}_{5} \mathrm{OH} \rightarrow \mathrm{CH}_{4}+\mathrm{CO}+\mathrm{H}_{2}, \mathrm{C}_{2} \mathrm{H}_{5} \mathrm{OH}+3 \mathrm{H}_{2} \mathrm{O} \leftrightarrow 2 \mathrm{CO}_{2}+6 \mathrm{H}_{2}, \\
\mathrm{CO}+3 \mathrm{H}_{2} \leftrightarrow \mathrm{CH}_{4}+\mathrm{H}_{2} \mathrm{O}
\end{gathered}
$$

The species participating in the above reactions, $\mathrm{C}_{2} \mathrm{H}_{5} \mathrm{OH}, \mathrm{CH}_{4}, \mathrm{CO}, \mathrm{CO}_{2}$, $\mathrm{H}_{2}$, and $\mathrm{H}_{2} \mathrm{O}$, will be represented by $j=1,2,3,4,5$ and 6 respectively. The matrices $\mathbf{M}, \mathbf{L}, \mathbf{P}, \mathbf{Q}$ and $\mathbf{X}$, and coefficients $(a, b, d)$ are constructed based on

435 the same procedure as earlier:

$$
\mathbf{M}=\left[\begin{array}{rrrrrr}
-1 & 1 & 1 & 0 & 1 & 0 \\
-1 & 0 & 0 & 2 & 6 & -3 \\
0 & 1 & -1 & 0 & -3 & 1
\end{array}\right]
$$

The coefficients $(a, b, d)$ for the species are as follows: $(2,3,1)$ for $j=1$, $(1,2,0)$ for $j=2,(1,0,1)$ for $j=3,(1,0,2)$ for $j=4,(0,1,0)$ for $j=5$, and $(0,1,1)$ for $j=6$. The complete vector $\mathbf{P}$ can therefore be formulated using Eq.(26) as $\mathbf{P}^{T}=\left[\begin{array}{llllll}6 & 4 & 1 & 0 & 1 & 0\end{array}\right]$. From section [3.2] and Eq.(25) 440 the following two independent reactions can be constructed:

$$
\begin{gathered}
\mathrm{C}_{2} \mathrm{H}_{5} \mathrm{OH}+3 \mathrm{H}_{2} \mathrm{O} \leftrightarrow 2 \mathrm{CO}_{2}+6 \mathrm{H}_{2}, \mathrm{CH}_{4}+2 \mathrm{H}_{2} \mathrm{O} \leftrightarrow \mathrm{CO}_{2}+4 \mathrm{H}_{2}, \\
\mathrm{CO}+\mathrm{H}_{2} \mathrm{O} \leftrightarrow \mathrm{CO}_{2}+\mathrm{H}_{2} .
\end{gathered}
$$


Thus,

$$
\mathbf{L}=\left[\begin{array}{rrrrrr}
-1 & 0 & 0 & 2 & 6 & -3 \\
0 & -1 & 0 & 1 & 4 & -2 \\
0 & 0 & -1 & 1 & 1 & -1
\end{array}\right]
$$

The matrices $\mathbf{M}, \mathbf{L}$ and $\mathbf{P}$ satisfy Eqs.(23) and (24). For ethanol as fuel $\mathbf{X}_{f}^{T}=$ $\left[\begin{array}{llllll}1 & 0 & 0 & 0 & 0 & 0\end{array}\right]$, and with $\mathbf{P}^{T}$ and $\mathbf{X}_{f}^{T}$ from above, Eq.(136) yields the same relationship as in Eq.(47). Similarly, from Eqs.(25) and (39), the complete

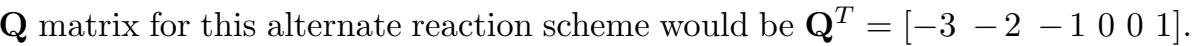
It can be verified that $\mathbf{Q}$ and $\mathbf{M}$ still satisfy Eq.(38). Thus, the complete $\mathbf{Q}$ matrix, and $\mathbf{X}_{f}^{T}$ will give the same relationship as in Eq.(48), upon substituting in Eq. (45). The example in sections 4.2.1 and 4.2 .2 demonstrates the invariance of $U_{s s}, S T C B_{s s}$ with respect to reaction schemes. This is reasonable since both variables $U$ and $S T C B$ are defined using conserved variables.

\section{Invariant Variables under Partial Oxidation (POX) Reforming}

In SOFC systems with oxidative reformers such as POX reformers, the observation made in section 3.2 that the potential hydrogen is conserved in the reforming process is no longer valid. Nevertheless, in this section we conduct an analytical study to investigate if invariant properties could still exist for POX reformer based SOFCs. A schematic diagram of a Partial Oxidation (POX) reformer based SOFC system is shown in Fig 3 . Within the POX reformer, the inlet fuel flow $\dot{N}_{f}$, inlet steam flow $\dot{N}_{s t}$, and inlet air flow $\dot{N}_{a i r}$, react to produce a hydrogen rich gas mixture that flows into the anode of the SOFC stack, $\dot{N}_{i n}$, wherein it is utilized to produce electricity.

Consider the same general class of hydrocarbons, formulated by $\mathrm{C}_{a} \mathrm{H}_{2 b} \mathrm{O}_{d}$, where $a, b$ and $d$ are non-negative integers and $a \neq 0$. Now consider the case where there are additional oxidation reactions in the POX reformer, of unknown reaction rates. We assume that the following oxidation reactions to take place in the reformer based on the discussion in literature, 25]: 


$$
\begin{gathered}
\mathrm{C}_{a} \mathrm{H}_{2 b} \mathrm{O}_{d}+[(a-d) / 2] \mathrm{O}_{2} \rightarrow a C O+b \mathrm{H}_{2} \\
\mathrm{C}_{a} \mathrm{H}_{2 b} \mathrm{O}_{d}+[(2 a+b-d) / 2] \mathrm{O}_{2} \rightarrow a \mathrm{CO}_{2}+b \mathrm{H}_{2} \mathrm{O} \\
\mathrm{H}_{2}+0.5 \mathrm{O}_{2} \rightarrow \mathrm{H}_{2} \mathrm{O} \text { (III) } \quad \mathrm{CO}+0.5 \mathrm{O}_{2} \rightarrow \mathrm{CO}_{2} \text { (IV). }
\end{gathered}
$$

In addition to the oxidation reactions mentioned above, steam reforming reaction also take place simultaneously in POX reformers, [57, 58]. Let us denote the net rate of consumption of fuel $\mathrm{C}_{a} \mathrm{H}_{2 b} \mathrm{O}_{d}$ through oxidation by $r_{o x}$. Consider $\lambda, \alpha$ and $\beta$ to be three variables such that $0 \leq \lambda, \alpha, \beta \leq 1$. Let $\lambda$ represents the fraction of oxidized fuel $\mathrm{C}_{a} \mathrm{H}_{2 b} \mathrm{O}_{d}$ that undergoes partial oxidation (I). Also, let $\alpha$ and $\beta$ represent the fractions of $\mathrm{H}_{2}$ and $\mathrm{CO}$ respectively, generated by (I), that undergo further oxidation through (III) and (IV). It is noted that the variables $\lambda, \alpha, \beta$, are considered unknown. Applying the above fractional conversions, the overall oxidation reaction is:

$$
\begin{array}{r}
C_{a} H_{2 b} O_{d}+[\lambda(a-d) / 2+(1-\lambda)(2 a+b-d) / 2+ \\
\alpha \lambda b / 2+\beta \lambda a / 2] O_{2} \rightarrow a \lambda(1-\beta) C O+b \lambda(1-\alpha) H_{2}+ \\
a[1-\lambda+\beta \lambda] C O_{2}+b[1-\lambda+\alpha \lambda] H_{2} O
\end{array}
$$

Note from Eq. (55) that since $\mathrm{C}_{a} \mathrm{H}_{2 b} \mathrm{O}_{d}$ is consumed through oxidation at the rate of $r_{o x}$, the rate of consumption of $\mathrm{O}_{2}$ is, $r_{o x}[\lambda(a-d) / 2+(1-\lambda)(2 a+b-$ d) $/ 2+\alpha \lambda b / 2+\beta \lambda a / 2]$. With a generic fuel of the form $\mathrm{C}_{a} \mathrm{H}_{2 b} \mathrm{O}_{d}$ undergoing POX reforming process, the main species that are expected in the gas mixture are $\mathrm{C}_{a} \mathrm{H}_{2 b} \mathrm{O}_{d}, \mathrm{CO}, \mathrm{CO}_{2}, \mathrm{H}_{2}, \mathrm{H}_{2} \mathrm{O}, \mathrm{N}_{2}$ and $\mathrm{O}_{2}$, which will be represented by ${ }_{480} j=1,2, \cdots 7$, in that order. From Eq.(27), we have the following conservation of mass equation for $\mathrm{O}_{2}$ (i.e. index $j=7$ ),

$$
\dot{N}_{\text {air }} \mathcal{X}_{7, a i r}-\dot{N}_{i n} \mathcal{X}_{7, r}+\mathcal{R}_{7, r}=0
$$

where,

$$
\mathcal{R}_{7, r}=-r_{o x}[\lambda(a-d) / 2+(1-\lambda)(2 a+b-d) / 2+\alpha \lambda b / 2+\beta \lambda a / 2] .
$$


We next make the observation that $\mathrm{O}_{2}$ is completely consumed in the reformer has no $\mathrm{O}_{2}$. This implies that $\mathcal{X}_{7, r}=0$ for all time. Therefore, from Eqs.(56) and (57), we have

$$
\dot{N}_{a i r} \mathcal{X}_{7, a i r}=r_{o x}\left[\frac{\lambda(a-d)}{2}+\frac{(1-\lambda)(2 a+b-d)}{2}+\frac{\alpha \lambda b}{2}+\frac{\beta \lambda a}{2}\right]=r_{o x} t_{o x}
$$

Since $\mathcal{X}_{7, \text { air }}=0.21$ and the air flow rate $\dot{N}_{\text {air }}$ can be assumed to be known, $r_{o x} t_{o x}$ will be known even though $r_{o x}$ and $t_{o x}$ are individually unknown. In the following discussion we will show that in the presence of oxidative reforming this information is sufficient to derive a steady-state equation for fuel utilization under certain additional conditions. The mass conservation equation for the reformer would be

$$
\frac{d}{d t}\left(N_{r} \mathbf{X}_{r}\right)=\dot{N}_{a i r} \mathbf{X}_{a i r}+\dot{N}_{f} \mathbf{X}_{f}+\dot{N}_{s t} \mathbf{X}_{s t}-\dot{N}_{i n} \mathbf{X}_{r}+\mathbf{R}_{r}^{T}+\mathbf{R}_{o x}^{T}
$$

where $\mathbf{R}_{r}$ and $\mathbf{R}_{o x}$ are vectors containing the rate of formation of species through steam reforming and oxidation reactions respectively. Equation (59) is similar to Eq.(28), with the exception that a recirculated flow $k \dot{N}_{o}$ is not considered and an air flow $\dot{N}_{a i r}$ is considered for the POX reformer shown in Fig 3 , Imposing steady-state conditions and pre-multiplying the above equation with $\mathbf{P}^{T}$, where $\mathbf{P}^{T}=\left[(2 a+b-d) \begin{array}{llllll}1 & 0 & 1 & 0 & 0 & 0\end{array}\right]$, we have

$$
0=\dot{N}_{f} \mathbf{P}^{T} \mathbf{X}_{f}-\dot{N}_{i n} \mathbf{P}^{T} \mathbf{X}_{r}+\mathbf{P}^{T} \mathbf{R}_{o x}^{T} .
$$

The potential hydrogen vector $\mathbf{P}$ remains the same as that described in section 3.2. and is constructed using Eq.(26). From sections 3.2 and 3.3, and noting that air does not contain a hydrogen source, we have $\mathbf{P}^{T} \mathbf{R}_{r}^{T}=\mathbf{P}^{T} \mathbf{X}_{s t}=\mathbf{P}^{T} \mathbf{X}_{a i r}=$ 0. In Eq. (60) we also note that

$$
\mathbf{X}_{f}=\left[\begin{array}{lllllll}
1 & 0 & 0 & 0 & 0 & 0 & 0
\end{array}\right]^{T} \Rightarrow \dot{N}_{f} \mathbf{P}^{T} \mathbf{X}_{f}=(2 a+b-d) \dot{N}_{f}
$$


Further, from Eq.(55) we have,

$$
\mathbf{R}_{o x}=\left[\begin{array}{c}
-1 \\
a \lambda(1-\beta) \\
a(1-\lambda+\beta \lambda) \\
b \lambda(1-\alpha) \\
b(1-\lambda+\alpha \lambda) \\
0 \\
-\{\lambda(a-d) / 2+(1-\lambda)(2 a+b-d) / 2+\alpha \lambda b / 2+\beta \lambda a / 2\}
\end{array}\right] r_{o x} .
$$

From Eqs.(58), (60), (61), and (62), we have

$$
\dot{N}_{i n} \mathbf{P}^{T} \mathbf{X}_{r}=(2 a+b-d) \dot{N}_{f}-2 r_{o x} t_{o x}=(2 a+b-d) \dot{N}_{f}-2 \dot{N}_{a i r} \mathcal{X}_{7, a i r}
$$

It can be seen that since $a, b, d, \dot{N}_{f}$ and $\dot{N}_{\text {air }} \mathcal{X}_{7, a i r}$ are known, the steady-state value of $\dot{N}_{i n} \mathbf{P}^{T} \mathbf{X}_{r}$ can be determined from Eq.(63) without a knowledge of the oxidation or steam-reforming reactions. Eq.(63) reduces to

$\dot{N}_{i n} \mathbf{P}^{T} \mathbf{X}_{r}=\dot{N}_{f}[(2 a+b-d)-2 a O 2 C] \quad \Rightarrow \quad O 2 C=\frac{\dot{N}_{a i r} X_{7, a i r}}{a \dot{N}_{f}}=\frac{0.21 \dot{N}_{a i r}}{a \dot{N}_{f}}$

where, we define the $\mathrm{O} 2 \mathrm{C}$ ratio as the molar ratio between oxygen and fuel $\mathrm{C}_{a} \mathrm{H}_{2 b} \mathrm{O}_{d}$ at the inlet of the reformer, which is considered known. Next, we note that under POX reforming, the mass conservation equation of the anode, given in Eq. 355), remains unchanged. This is because we assume the internal reforming in the anode to consist only of steam reforming and no oxidative reforming. This is consistent with our earlier assumption that all oxygen is consumed in the POX reformer itself through Eq.(55). Therefore, from the definition of $U$ in Eq.(22) and combining Eqs.(8), (35) and (64) we have the following invariant relationship for steady-state fuel utilization $U_{s s}$ for a POX reformer based SOFC system: 
$U_{s s}=r_{e} / \dot{N}_{f}[(2 a+b-d)-2 a O 2 C]=\left(i \mathcal{N}_{\text {cell }} / n F \dot{N}_{f}\right)[(2 a+b-d)-2 a O 2 C]$

The above result implies that for simple hydrocarbons conforming to the struc-

to satisfy both conditions. If $i$ is assumed to be a given rather than a variable, since $i$ would depend upon the power demand, then the potential variables that could be manipulated are $\dot{N}_{f}, \dot{N}_{s t}$ and $k$. This implies a family of solutions. If $k$ 
is fixed and $\dot{N}_{s t}$ is absent, as in our sample SOFC, then it is evident that we can achieve only one of $U_{s s}$ and $S T C B_{s s}$. In that case, for a specific SOFC system, one can fix a target value of $U_{s s}$ and simply attempt to satisfy $S T C B>0,37$.

An interesting relation is obtained upon eliminating $i$ from Eqs.(36) and (45). We get the following relation:

$$
U_{s s}=\frac{1-k}{k} \frac{(1-k) S T C B_{s s}-\dot{N}_{f} \mathbf{Q}^{T} \mathbf{X}_{f}-\dot{N}_{s t}}{\dot{N}_{f} \mathbf{P}^{T} \mathbf{X}_{f}-(1-k) S T C B_{s s}+\dot{N}_{f} \mathbf{Q}^{T} \mathbf{X}_{f}+\dot{N}_{s t}} .
$$

Additionally, if there is no external steam input, i.e. $\dot{N}_{s t}=0$ and if we impose the condition $S T C B_{s s}>0$, then we obtain the following constraint on $U_{s s}$

$$
U_{s s}>\frac{1-k}{k} \frac{-\mathbf{Q}^{T} \mathbf{X}_{f}}{\mathbf{P}^{T} \mathbf{X}_{f}+\mathbf{Q}^{T} \mathbf{X}_{f}}
$$

Thus, if steam is generated by electrochemical reactions only, then higher utilization and/or high recirculation $k$ must be used to maintain a healthy STCB (and hence STCR). This is expected and Eq.67) quantifies it. It is interesting to note here that Eq.(67) is independent of $\dot{N}_{f}$. This is because from Eq.(45), the conditions $\dot{N}_{s t}=0$ and $S T C B_{s s}=0$ result in a unique value of $\dot{N}_{f}$.

\section{2. $S T C B$ in Anode}

Since steam reforming and electrochemical reactions occur simultaneously in the anode, its STCB is of interest. It is however anticipated that the STCB is of lesser concern in the anode than in the reformer, since steam supply is maintained in the anode by electrochemical reactions. Nevertheless, we carry out an analysis for quantitative comparison. The definition of anode STCB would be similar to that of the reformer in Eq.(18), i.e.

$$
S T C B_{a} \triangleq \text { Excess steam at anode inlet. }
$$

Based on the definition above, $S T C B_{a}$ can be formulated as

$$
S T C B_{a}=\dot{N}_{i n} \mathbf{Q}^{T} \mathbf{X}_{r}+\mathbf{Q}^{T} \mathbf{R}_{e}^{T}
$$

From, Eqs.(8), (41), (42), (44) and (69), we get the following steady-state STCB 
at the anode:

$$
S T C B_{s s, a}=\frac{1}{1-k}\left[\dot{N}_{f} \mathbf{Q}^{T} \mathbf{X}_{f}+\dot{N}_{s t}+\frac{i \mathcal{N}_{c e l l}}{n F}\right] .
$$

Thus, from Eqs. (45) and (70) we observe that

$$
S T C B_{s s, a}-S T C B_{s s}=r_{e}=\frac{i \mathcal{N}_{\text {cell }}}{n F}>0
$$

which confirms that STCB is higher at anode than the reformer and the difference dictated by the current draw. Simulation results depicted in Fig 4 further demonstrate that for the SOFC system described in section 2 , predicting/monitoring $S T C B$ in the reformer is more important than that in the anode. We note in Fig 4 that both STCB and STCR are considerably higher in the anode. Thus, the analysis and simulation in this section show that fuel utilization $U$ and the steam-to-carbon-balance STCB are the critical performance variables for the anode and the reformer respectively.

\section{Conclusions}

We have shown that for reformer based SOFC systems, steady-state fuel utilization $U$ is related to the system inputs, namely the composition and flow rate of unreformed fuel and current draw, through an analytical relationship. The relationship is invariant with respect to reforming reactions, their rates, internal flow rates, temperatures and pressures. We show that it can be derived without a specific mathematical model of the SOFC system and without knowledge of the reforming reactions. We derive a similar invariant relationship for the steamto-carbon-balance $(S T C B)$ of the reformer. Together, the two relations can be used to predict safe and optimal conditions in the anode and reformer. Analysis indicated that variables for which such invariant relationship exist, such as $U$ and $S T C B$, are defined using conserved quantities. For instance, the invariant property of $U$ and $S T C B$ are attributed to their definitions based on potential hydrogen and potential steam, both of which are conserved quantities in steam reforming. The study is generalized for hydrocarbon fuels that conform to the 
formula $\mathrm{C}_{a} \mathrm{H}_{2 b} \mathrm{O}_{d}$, with integer valued and non-negative $a, b, d$, and $a \neq 0$. The proposed methodology is verified for simple hydrocarbon fuels and fuel mixtures by using reaction schemes obtained from literature. It is shown that when both $\mathrm{H}_{2}$ and $\mathrm{CO}$ participate in electrochemical reactions in unknown proportions, the resulting steady-state invariant relationships remain unchanged. We also show ${ }_{95}$ the existence of the invariant property in SOFCs with oxidative reforming, such as POX reformers. Thus the application and use of invariant properties appears to go beyond just steam reforming. The extension of this approach to higher hydrocarbons requires further investigation. The ability to predict steady-state $U$ and $S T C B$ based on input conditions and without the use complicated and often nonlinear dynamical equations is advantageous, since it allows us to determine operating points that are safe for both the fuel cell and the reformer. These equations elucidate the influences of both STCR and recirculation on reformer-based SOFC systems from a performance standpoint. The application of invariant properties can be extended to transient control of $U$. This enables operating SOFCs in a load-following mode while reducing the electrical storage capacity needed to handle transient power demands.

\section{Acknowledgments}

The authors gratefully acknowledge the support from ONR under grant \#N0001 40910272 and NSF under grant \#1158845 in conducting this research.

\section{References}

[1] S. C. Singhal, K. Kendall, High Temperature Solid Oxide Fuel Cells: Fundamentals, Design and Applications, Elsevier, 2003.

[2] K. Huang, J. B. Goodenough, Solid Oxide Fuel Cell Technology, CRC Press, 2009.

[3] H. Iwai, Y. Yamamoto, M. Saito, H. Yoshida, Numerical simulation of intermediate-temperature direct-internal-reforming planar solid oxide fuel cell, Energy 36 (2011) 2225-2234. 
[4] J. Larminie, A. Dicks, Fuel Cell Systems Explained, 2nd Edition, John Wiley \& Sons Ltd., Chichester, West Sussex, England, 2003.

[5] X. Li, Principles of Fuel Cells, Taylor and Francis, 2006.

[6] M. Rokni, Thermodynamic analysis of SOFC (solid oxide fuel cell)-stirling hybrid plants using alternative fuels, Energy 61 (2013) 87-97.

[7] D. Saebea, S. Authayanun, Y. Patcharavorachot, W. Paengjuntuek, A. Arpornwichanop, Use of different renewable fuels in a steam reformer integrated into a solid oxide fuel cell: Theoretical analysis and performance comparison, Energy 51 (2013) 305-313.

[8] J. R. Meacham, F. Jabbari, J. Brouwer, J. L. Mauzey, G. S. Samuelsen, Analysis of stationary fuel cell dynamic ramping capabilities and ultra capacitor energy storage using high resolution demand data, Journal of Power Sources 156 (2006) 472-479.

[9] A. Drolia, P. Jose, N. Mohan, An approach to connect ultracapacitor to fuel cell powered electric vehicle and emulating fuel cell electrical characteristics using switched mode converter, Proceedings of Industrial Electronics Conference (2003) 897-901.

[10] P. Thounthong, S. Rael, B. Davat, Control strategy of fuel cell/supercapacitors hybrid power sources for electric vehicle, Journal of Power Sources 158 (2006) 806-814.

[11] A. Vahidi, A. Stefanopoulou, H. Peng, Current management in a hybrid fuel cell power system: A model-predictive control approach, IEEE Transactions on Control Systems Technology 14 (6) (2006) 1047-1057.

[12] F. Mueller, J. Brouwer, F. Jabbari, S. Samuelsen, Dynamic simulation of an integrated solid oxide fuel cell system including current-based fuel flow control, Journal of Fuel Cell Science and Technology 3 (2) (2006) 144-154. 
[13] W. Schmittinger, A. Vahidi, A review of the main parameters influencing long-term performance and durability of PEM fuel cells, Journal of Power Sources 180 (2008) 1-14.

[14] A. Reinert, T. Strohbach, Determination of the global/local fuel utilization via variation of the fuel utilization, ECS Transactions 25 (2) (2009) 811814.

[15] A. Lazzaretto, A. Toffolo, F. Zanon, Parameter setting for a tubular SOFC simulation model, Journal of Energy Resources Technology 126 (1) (2004) $40-46$.

[16] K. Sedghisigarchi, A. Feliachi, Control of grid-connected fuel cell power plant for transient stability enhancement, Proceedings of the IEEE Power Engineering Society Winter Meeting 1 (2002) 383-388.

[17] S. Campanari, Thermodynamic model and parametric analysis of a tubular SOFC module, Journal of Power Sources 92 (2001) 26-34.

[18] D. P. Xenos, P. Hofmann, K. D. Panopoulos, E. Kakaras, Detailed transient thermal simulation of a planar SOFC (solid oxide fuel cell) using gPROMS, Energy 81 (2015) 84-102.

[19] C. Stiller, B. Thorud, O. Bolland, R. Kandepu, L. Imsland, Control strategy for a solid oxide fuel cell and gas turbine hybrid system, Journal of Power Sources 158 (1) (2006) 303-315.

[20] M. H. Nehrir, C. Wang, Modeling and Control of Fuel Cells - Distributed Generation Applications, John Wiley and Sons, Inc., Hoboken, New Jersey, 2009.

[21] A. K. M. M. Murshed, B. Huang, K. Nandakumar, Estimation and control of solid oxide fuel cell system, Computers and Chemical Engineering 34 (2010) 96-111. 
[22] R. Gaynor, F. Mueller, F. Jabbari, J. Brouwer, On control concepts to prevent fuel starvation in solid oxide fuel cells, Journal of Power Sources 180 (1) (2008) 330-342.

[23] R. Kandepu, L. Imsland, B. A. Foss, C. Stiller, B. Thorud, O. Bolland, Modeling and control of a SOFC-GT-based autonomous power system, Energy 32 (4) (2007) 406-417.

[24] H. Gorgun, M. Arcak, S. Varigonda, S. A. Bortoff, Observer designs for fuel processing reactors in fuel cell power systems, International Journal of Hydrogen Energy 30 (2005) 447-457.

[25] J. T. Pukrushpan, A. G. Stefanopoulou, H. Peng, Control of Fuel Cell

[29] A. Arce, A. J. del Real, C. Bordons, MPC for battery/fuel cell hybrid vehicles including fuel cell dynamics and battery performance improvement, Journal of Process Control 19 (8) (2009) 1289-1304.

[30] D. Bhattacharyya, R. Rengaswamy, A review of solid oxide fuel cell (SOFC) dynamic models, Industrial and Engineering Chemistry Research 48 (13) (2009) 6068-6086. 
[31] B. Huang, Y. Qi, M. Murshed, Solid oxide fuel cell: Perspective of dynamic modeling and control, Journal of Process Control 21 (10) (2011) 1426-1437. doi:http://dx.doi.org/10.1016/j.jprocont.2011.06.017.

[37] T. Das, S. Narayanan, R. Mukherjee, Steady-state and transient analysis of a steam reformer based solid oxide fuel cell system, ASME Journal of Fuel Cell Science and Technology 7 (1).

[38] T. Allag, T. Das, Robust control of solid oxide fuel cell ultra-capacitor hybrid system, IEEE Transactions on Control Systems Technology 20 (1) (2012) 1-10.

[39] F. Mueller, F. Jabbari, R. Gaynor, J. Brouwer, Novel solid oxide fuel cell system controller for rapid load following, Journal of Power Sources 172 (2007) 308-323. 
[40] S. Ahmed, M. Krumpelt, Hydrogen from hydrocarbon fuels for fuel cells, International Journal of Hydrogen Energy 26 (4) (2001) 291-301.

[41] X.-F. Ye, J. Zhou, S. R. Wang, F. R. Zeng, T. L. Wen, Z. L. Zhan, Research of carbon deposition formation and judgment in $\mathrm{Cu}-\mathrm{CeO}_{2}-\mathrm{ScSZ}$ anodes for direct ethanol solid oxide fuel cells, International Journal of Hydrogen Energy 37 (1) (2012) 505-510.

[42] A. Babaei, L. Zhang, E. Liu, S. P. Jiang, Performance and carbon deposition over $\mathrm{Pd}$ nanoparticle catalyst promoted Ni/GDC anode of sofcs in methane, methanol and ethanol fuels, International Journal of Hydrogen Energy 37 (20) (2012) 15301-15310.

[43] J. W. Yun, S. P. Yoon, H. S. Kim, J. Han, S. W. Nam, Effect of $\mathrm{Sm}_{0} .2 \mathrm{Ce}_{0} .8 \mathrm{O}_{1} .9$ on the carbon coking in ni-based anodes for solid oxide fuel cells running on methane fuel, International Journal of Hydrogen Energy 37 (5) (2012) 4356-4366.

[44] X. Zhang, Y.-M. Wu, A control-oriented dynamic model adapted to variant steam-to-carbon ratios for an sofc with exhaust fuel recirculation, Fuel Cells 11 (2) (2011) 200-211.

[45] T. S. Lee, J. N. Chung, Y.-C. Chen, Design and optimization of a combined fuel reforming and solid oxide fuel cell system with anode off-gas recycling, Energy Conversion and Management 52 (10) (2011) 3214-3226.

[46] R. Peters, R. Deja, L. Blum, J. Pennanen, J. Kiviaho, T. Hakala, Analysis of solid oxide fuel cell system concepts with anode recycling, International Journal of Hydrogen Energy 38 (16) (2013) 6809-6820.

[47] M. L. Ferrari, A. Traverso, L. Magistri, A. F. Massardo, Influence of the anodic recirculation transient behaviour on the SOFC hybrid system performance, Journal of Power Sources 149 (2005) 22-32. 
[48] A. Y. Karnik, J. Sun, Modeling and control of an ejector based anode recirculation system for fuel cells, Proceedings of ASME Fuel Cell 2005 (2005) 721-731.

[49] J. Xu, G. F. Froment, Methane steam reforming, methanation and watergas shift: I. Intrinsic kinetics, AIChE Journal 35 (1) (1989) 88-96.

[50] R. Bove, P. Lunghi, N. M. Sammes, SOFC mathematic model for systems simulations-part 2: definition of an analytical model, International Journal of Hydrogen Energy 30 (2) (2005) 189-200.

[51] U. K. Chakraborty, An evolutionary computation approach to predicting output voltage from fuel utilization in SOFC stacks, 2009 IEEE Congress on Evolutionary Computation, CEC 2009 (2009) 2165-2171.

[52] T. Bertelsen, T. Pedersen, J. Poulsen, R. Schultz, Modelling and optimization of solid oxide fuel cell system, Aalborg University (2011).

[53] S. Ahmed, J. Kopasz, R. Kumar, M. Krumpelt, Water balance in a polymer electrolyte fuel cell system, Journal of Power Sources 112 (2002) 519-530.

[54] A. Vizcaino, A. Carrero, J. Calles, Hydrogen production by ethanol steam reforming over cu-ni supported catalysts, International Journal of Hydrogen Energy 32 (10-11) (2007) 1450-1461.

[55] S. Tosti, A. Basile, R. Borelli, F. Borgognoni, S. Castelli, M. Fabbricino, F. Gallucci, C. Licusati, Ethanol steam reforming kinetics of a pd-ag membrane reactor, International Journal of Hydrogen Energy 34 (11) (2009) $4747-4754$.

[56] M. S. Batista, R. K. S. Santos, E. M. Assaf, J. M. Assaf, E. A. Ticianelli, Characterization of the activity and stability of supported cobalt catalysts for the steam reforming of ethanol, Journal of Power Sources 124 (1) (2003) 99-103. 
[57] R. Horn, K. A. Williams, N. J. Degenstein, L. D. Schmidt, Syngas by catalytic partial oxidation of methane on rhodium: Mechanistic conclusions from spatially resolved measurements and numerical simulations, Journal of Catalysis 242 (1) (2006) 92-102.

[58] R. Horn, K. A. Williams, N. J. Degenstein, L. D. Schmidt, Mechanism of $\mathrm{H}_{2}$ and $\mathrm{CO}$ formation in the catalytic partial oxidation of $\mathrm{CH}_{4}$ on $\mathrm{Rh}$ probed by steady-state spatial profiles and spatially resolved transients, Chemical Engineering Science 62 (5) (2007) 1298-1307. 


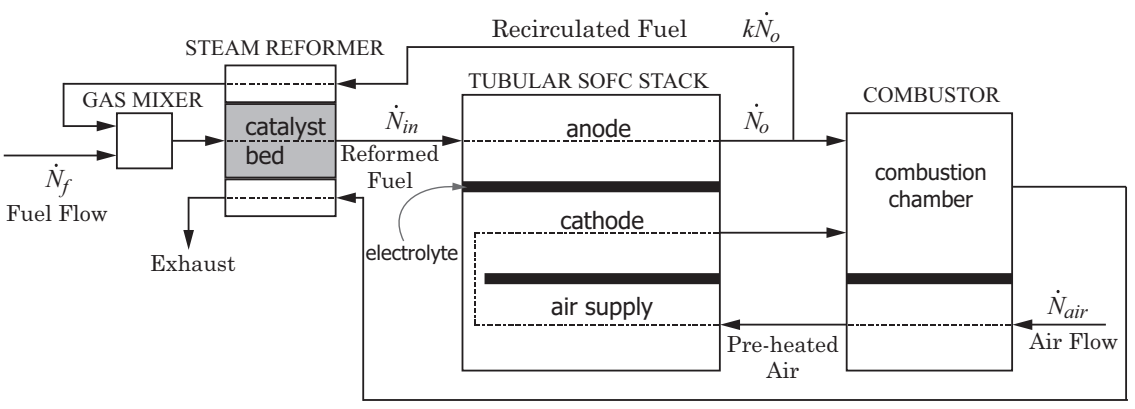

Figure 1: Schematic Diagram of Sample SOFC System 


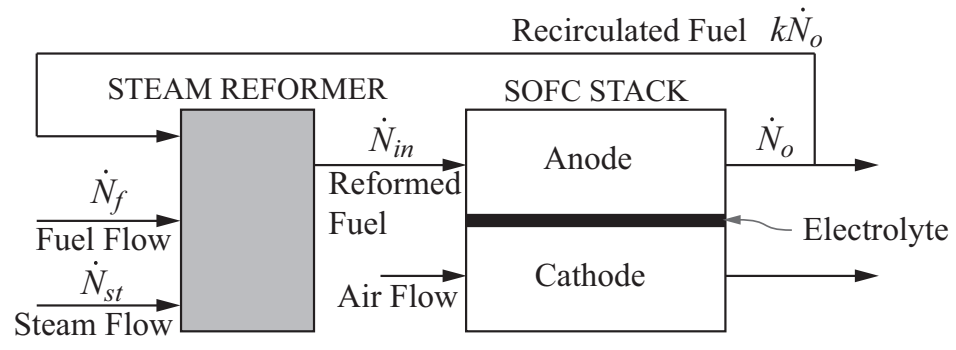

Figure 2: General SOFC System Diagram 


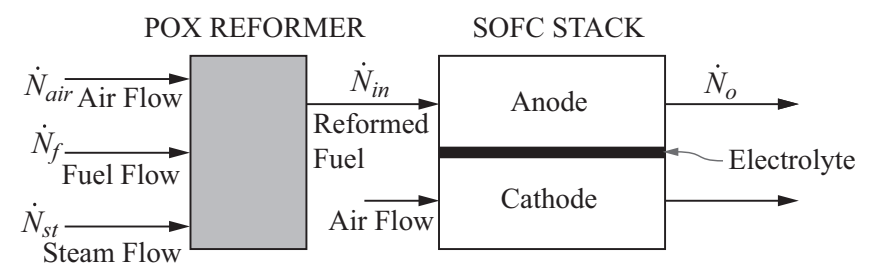

Figure 3: POX-SOFC System Diagram 

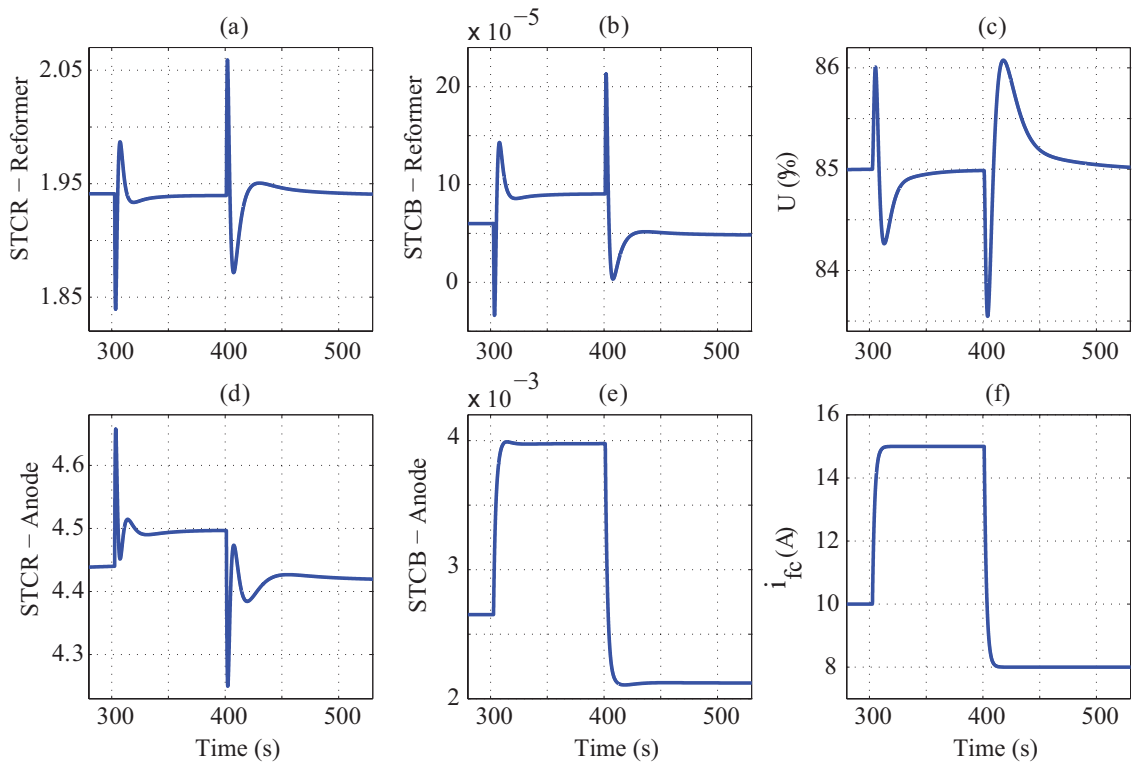

Figure 4: COMPARISON OF STCR AND STCB IN REFORMER AND STACK 